\title{
Empregabilidade dos administradores: quais os perfis profissionais demandados pelas empresas?
}

\section{Manager's employability: defining the professional profiles wanted by organizations}

\author{
Ana Heloísa da Costa Lemos ${ }^{1}$ \\ Mario Couto Soares Pinto ${ }^{2}$
}

\section{Resumo}

Esta investigação se propõe a analisar o tipo de funcionário recém-formado que grandes empresas privadas procuram para compor seu quadro gerencial. Parte da hipótese de que existe um conjunto de qualificações técnicas e comportamentais que estão mais ou menos alinhadas com as necessidades mercadológicas que envolvem essas corporações e que nem sempre encontram respaldo na formação oficial de um curso de graduação em administração de empresas. Para identificar os requisitos valorizados pelas empresas em seu processo de seleção de candidatos a cargos da área gerencial, foram entrevistadas oito pessoas-chave da área de recursos humanos de grandes empresas, responsáveis pela condução de processos seletivos estruturados. A pesquisa conclui que a formação cognitiva específica recebida pelo graduando não é fator decisivo na contratação, mas, sim, as variáveis comportamentais e vivenciais do aspirante ao cargo e a excelência da instituição de ensino cursada.

Palavras-chave: empregabilidade; qualificação profissional; perfil do administrador.

Abstract

The objective of this paper is to analyze what kind of newly graduated manager big private companies are looking for. The hypothesis behind the study is that there is a group of technical and behavioral qualifications that are aligned with business demands and that these qualifications are often ignored by businesses undergraduate courses. Data collection was made through interviews with eight people from big Brazilian private companies which are responsible for recruitment-related activities. The conclusion is that the knowledge acquired by students during their undergraduate courses does not contribute significantly to their employment, being more important their behavior and life history characteristics as well as the prestige of their undergraduate course.

Key words: employability; professional qualification; manager profile.

\footnotetext{
${ }^{1}$ Doutora em Sociologia pelo IUPERJ. Professora do quadro principal da PUC-Rio.Endereço: Rua Marques de São Vicente 225 - Gávea - Rio de Janeiro/RJ Brasil -CEP: 22451900 - Email: ah.lemos@uol.com.br

2 Doutor em Administração pela PUC-Rio. Coordenador do curso de Graduação em Administração da PUC-Rio. Professor do quadro principal da PUC-Rio. Endereço: Rua Marques de São Vicente 225 - Gávea-Rio de J aneiro/RJ - Brasil -CEP: 22451900 - Email: mpinto@iag.puc-rio.br

Artigo submetido em outubro de 2007 e aceito em junho de 2008
} 


\section{Introdução}

O processo de reestruturação produtiva atualmente em curso tem provocado mudanças significativas na forma como se organiza o mercado de trabalho, mudanças estas que têm criado um cenário de crescimento dos índices de desemprego aberto e precarização do emprego, ${ }^{1}$ afet ando a forma como as pessoas gerenciam suas trajetórias profissionais. Essas transformações têm aparecido no centro da discussão sobre o mercado de trabalho na qual se engajam estudiosos de diferentes orientações teóricas e ideológicas.

Apesar da crise do emprego ser o tema comum na maior parte das formulações contemporâneas acerca do mercado de trabalho, estas não convergem quando se trata de apontar as causas e, conseqüentemente, as saídas para o problema em análise. Para autores como Castel (1998) e Rifkin (1995), a reestruturação produtiva - na medida em que permite que se produza mais, com menos mão-de-obra - é a principal responsável pelo decréscimo da oferta de postos de trabalho. Já Coutinho (1997) e Pochmann (2001) vêem a reestruturação produtiva associada à globalização econômica como causadoras do desemprego, notadamente, nos países periféricos. Uma terceira vertente - representada no Brasil por economistas como Amadeo (1998), Neri, Camargo e Reis (1999) e Barros, Cossio e Teles (2001) - atribui à conjugação reestruturação produtiva e despreparo dos trabalhadores para assumir os novos postos de trabalho, a responsabilidade pelo crescente desemprego.

No caso brasileiro, observa-se que essa terceira vertente vem se constituindo na principal orientadora da discussão pública sobre o problema do desemprego. Essa é a versão com mais visibilidade na imprensa, além de ter orientado a política pública de maior abrangência elaborada no passado recente pelo Ministério do Trabalho e Emprego (MTE) para enfrentar a crise de desemprego contemporânea: o Plano Nacional de Qualificação do Trabalhador (Planfor). ${ }^{2}$

A versão que atribui à precária qualificação dos trabalhadores a responsabilidade pelos elevados índices de desemprego delineia a crise contemporânea do mercado de trabalho como um problema de oferta inadequada de força de trabalho. A partir desse panorama, intensificam-se os esforços individuais e institucionais com vistas a adequar a formação profissional à demanda do mercado de trabalho. A expectativa por se atingir a empregabilidade passa a orientar tanto as aspirações do jovem profissional, ansioso por garant ir sua vaga nesse disputado mercado, quanto as ações das instituições de ensino superior (IES) visando aumentar as chances de seu egresso se inserir no mundo produtivo.

Nesse contexto, o universo gerencial configura-se como um dos mais afetados por essas preocupações, motivo pelo qual a formação profissional do administrador de empresas tem sido alvo de intenso debate no âmbito das instituições de ensino dedicadas a prover essa formação. A preocupação em pensar o papel do administrador em face dos desafios de um mercado cada vez mais exigente tem motivado tanto estudos sobre o tema, quanto experiências inovadoras nas inst it uições de ensino superior, com vistas à adequação dos conteúdos ministrados nos cursos de graduação em administração às exigências do mercado e de uma legislação em constante mutação.

Apesar da preocupação crescente com o tema e da valorização da questão da empregabilidade pelas empresas, IES e estudantes, nem sempre são claras as indicações quanto ao que efet ivamente se considera ser empregável, no âmbito gerencial. A percepção da imprecisão das informações referentes aos perfis profissionais efetivamente demandados pelos empregadores ao contratarem seus gerentes/administradores motivou a realização deste estudo.

Sem a pretensão de oferecer respostas definitivas a essa indagação, buscou-se identificar as exigências de qualificação feitas por empresas privadas ao contratarem seus futuros gerentes. Conhecer suas exigências é um caminho para entender os critérios adotados pelas empresas ao selecionarem seus funcionários, contribuindo, assim, para o delineamento do perfil do profissional empregável, na área de administração de empresas. Pretende-se, assim, oferecer uma contribuição aos profissionais que at uam ou pretendem at uar na área gerencial das grandes empresas, bem como às IES em seu esforço para aproximar a formação oferecida aos futuros administradores das exigências do mercado de trabalho. 
Para lograr esse objetivo, este artigo está estruturado em cinco seções. Na primeira, apresenta-se, em linhas gerais, o universo e a metodologia de pesquisa do estudo. Na segunda, procura-se sintetizar os termos do debate acadêmico sobre o que faz um profissional ser empregável, nos dias de hoje, para permitir a análise dos depoimentos dos profissionais do mercadb entrevistados vis-à-vis às cat egorias dominantes no referido debate. A terceira seção apresenta e discute algumas experiências recentes de instituições de ensino superior brasileiras visando adequar seus cursos de administração de empresas às exigências do mercado de trabalho. Na quarta seção, são sintetizadas as informações provenientes das entrevistas realizadas com profissionais responsáveis pelos processos de seleção de grandes empresas privadas, com ênfase nos requisitos apontados como decisivos na escolha dos futuros ocupantes de cargos administrativos e gerenciais dessas organizações. A última seção apresenta as conclusões acerca do que faz um candidato ser empregável aos olhos das empresas pesquisadas.

\section{A pesquisa}

\section{Universo e amostra}

Tendo em vista o tamanho e a diversidade do setor que se pretende pesquisar, para efeitos de investigação, optou-se por focalizar somente as organizações com mais de 100 funcionários. A hipótese que norteou esse critério é a de que pequenas empresas nem sempre dispõem de um processo de recrutamento e seleção estruturado, o que poderia mascarar os resultados da investigação. Dessa forma, foram enviados formulários por meio eletrônico para diversas empresas fluminenses privadas, cujo pessoal de recursos humanos compõe um fórum de discussão conhecido como Grupo Executivo de Recursos Humanos, que congrega empresas diversas para a troca de experiências na área de recursos humanos. A int enção dessa abordagem foi tanto travar um primeiro contato com a percepção de decisores de recursos humanos sobre o tema, quanto sondar a disponibilidade das entrevistas que se seguiriam. Nesses formulários era solicitado ao respondente priorizar conhecimentos e competências esperados de um futuro gestor. Dos mais de 30 formulários enviados, vários voltaram sem resposta, provavelmente, por conta de alterações nos endereços eletrônicos ou troca da pessoa encarregada. No total, 17 formulários foram adequadamente preenchidos e devolvidos. Esse grupo de empresas foi contactado por telefone e solicitada uma entrevista em profundidade, ficando clara a intenção dos pesquisadores em inquirir sobre as exigências relativas aos futuros ocupantes de cargos de gestão. Por questões de agenda, apenas seis gestores da área de recursos humanos puderam ser entrevistados, estando eles vinculados às áreas bancária, de navegação, da indústria química (duas empresas) e de telecomunicações (duas empresas). Juntaram-se a esse grupo duas empresas de consultoria com forte at uação na contrat ação de trainees de gerência. Tais contatos foram realizados por indicação dos próprios participantes do grupo principal.

\section{Obtenção dos dados}

Sete das oito entrevistas ocorreram no local de trabalho do entrevistado, sendo gravadas com seu conhecimento e autorização. A outra entrevista ocorreu fora do espaço físico da empresa, em local sugerido pelo entrevistadb, com a presença de ambos os pesquisadores, sendo igualmente gravada. Todas as entrevistas foram semiestruturadas, com um roteiro padrão de questões relevantes à investigação, mas que sofria adaptações conforme o andamento das conversas, visando privilegiar a linha de raciocínio do entrevistado. A opção por esse tipo de abordagem deveu-se à necessidade de não direcionar as respostas dos entrevistados, tornando-as mais livres e espontâneas. Para a estrut uração das questões tratadas nas entrevistas fez-se relevante as respostas coletadas nos formulários previamente enviados. Não obstante, os resultados oriundos dessa ferramenta não fazem parte do corpo principal de informações consideradas para essa pesquisa.

De uma maneira geral, todas as argüições permitiram uma rica extração de informações de cada entrevistadb. Não houve qualquer limitação em relação a tempo, nem interrupções por conta de trabalho, ou mesmo incômodos por, muitas vezes, serem tratados temas estratégicos das empresas. Deve ser ressaltado que tais condições não são freqüentes em investigações de campo que envolvem empresas e profissionais em seus ambientes de trabalho, o que permitiu, nesse caso específico, aprofundar a inquirição até o nível desejado pelos pesquisadores. De modo geral, cada entrevista durou cerca de uma hora, mas houve casos em que esse período foi largamente ultrapassado. Foi possível também perceber que se criou uma empatia entre entrevistadores e 
entrevistados, o que proporcionou a espontaneidade e o relaxamento pretendidos, garantindo, assim, maior qualidade às respostas obtidas e uma livre associação entre os temas abordados.

\section{Tratamento dos dados}

Feitas as entrevistas e coletados os dados, as informações então obtidas foram cruzadas com as que já estavam disponíveis, sendo assinalados os pontos em comum. Para isso, foi fundamental ouvir tantas vezes quantas necessárias, as gravações dessas entrevistas. Nexos causais entre os diversos temas abordados foram estabelecidos e um quadro geral foi montado pelos pesquisadores. Havendo clara convergência de idéias, buscava-se situá-la no cenário em estruturação. Tal procedimento foi repetido até que não fosse mais visível a contribuição de determinada fala comum para a montagem do mapa de relacionamentos proposto. Nesse ponto, buscava-se outro tópico recorrente e, assim, sucessivamente, até terem sido esgotados. As peculiaridades de cada empresa ou profissional entrevistado foram relegadas a um segundo plano, dado que o interesse recaía sobre o geral e não sobre o específico. Todavia, algumas falas suscitam interesse quando expressam algo que bem representa o todo. Nesses casos, são apontadas no decorrer do estudo.

\section{A conquista da empregabilidade: notas do debate acadêmico}

Do debate acadêmico recente acerca das exigências feitas pelo setor produtivo aos trabalhadores que anseiam por obter uma vaga no mercado de trabalho emergem as principais categorias teóricas que permitem mapear o perfil desse novo profissional. Esta seção procura sintetizar os termos desse debate de forma a permitir a análise dos depoimentos dos profissionais do mercado entrevistados vis-à-vis às cat egorias dominantes no referido debate.

\section{O modelo de competências}

No debate atual sobre a importância da qualificação profissional, o termo competência ganha destaque, sugerindo uma ruptura com a noção tradicional de qualificação. Enquanto esta diz respeito ao conjunto de capacidades e conhecimentos que o trabalhador deve assumir para ocupar um posto de trabalho, o modelo de competências pressupõe uma nova atitude do trabalhador com relação ao trabalho. Esse modelo tem como principal referência o debate que vem ocorrendo na França nos últimos anos acerca das competências individuais que passam a ser exigidas pela nova forma de gerir as empresas, denominada "gestão pela competência”.

Para discutir o sentidb que considera adequado ao termo, Zarifian (1998) inicia seu artigo definindo o que seria a abordagem tradicional, centrada na qualificação do indivíduo, abordagem coerente com o taylorismo e a organização burocrática da produção. Apesar de ainda ser dominante na França, a abordagem das qualificações contrastaria com o modelo de competências. Este se delineia a partir da crise do taylorismo e fordismo, pressupondo, por um lado, "um assumir de responsabilidade pessoal do assalariado diante das situações produtivas” (ZARIFIAN, 1998, p.19) - o que exige do trabalhador capacidade de enfrentar e responder a eventos imprevistos - e, por outro, “o exercício sistemático de uma reflexividade no trabalho" - entendida como "um distanciamento crítico vis-à-vis de seu trabalho, o fato de que a pessoa freqüentemente questiona sua maneira de trabalhar e os conhecimentos que ela mobiliza” (ZARIFIAN, 1998, p.20).

Tendo como base essas definições, o autor destaca que ambas as exigências referem-se muito mais a atitudes sociais do que a conhecimentos profissionais acumulados. Assim, Zarifian (1998, p.21) afirma que "aumentar a competência é, antes de tudo, criar as melhores condições possíveis para que os trabalhadores aceit em assumir responsabilidades e se mobilizar subjetivamente”.

Ao destacar a dimensão subjetiva da mobilização da competência, o autor não ignora o processo de aquisição de competências e chama at enção para as limitações dos modelos de aprendizagem vigentes, o escolar e o baseado na experiência, posto que delineados para atender às necessidades do modelo baseado na lógica das qualificações. O modelo de competências requer novas formas de aprendizagem, que contemplem dois momentos. O primeiro diz respeito ao "tempo de confrontação com situações reais que ocorrem no cotidiano 
do trabalho, com a condição de [se] ter [...] cuidado e [...] tempo [para] capitalizar as aquisições dessa confrontação". O segundo momento refere-se à formação através de estágios, que permita "acompanhar os assalariados para que eles possam se confrontar, seja com uma nova situação profissional, seja [com o reexame e o questionament o de] sua maneira de se encarregar das situações já conhecidas” (ZARIFIAN, 1998, p.22).

Ao referir-se ao modelo de gestão de competências efetivamente adotado em algumas empresas francesas, o autor aponta, para os operários de produção, três domínios de competências, a saber:

- as competências técnicas - que dizem respeito ao domínio dos processos e dos equipamentos, com uma forte tendência a associar competências de fabricação e competências na manutenção de equipamentos;

- as competências de gestão - que atualmente focalizam a gestão de qualidade e a gestão dos fluxos (planejamento e seqüenciamento da produção); e

- as competências de organização - que se concentram em dois domínios, a comunicação e a iniciativa/autonomia (ZARIFIAN, 1998, p.23).

Ao concluir sobre os méritos do modelo de competências, Zarifian (1998, p.24) ressalta tratar-se, acima de tudo, de um modo de gestão da empresa, visto que "gerir as competências” pressupõe "gerir pela competência”, o que requer "uma revisão das políticas de formação profissional e, sobretudo, sua articulação com as opções de organização do trabalho”.

Seguindo os passos de Zarifian, Hirata (1998) e Moraes (1999) chamam atenção para o fato do referido modelo ser originário do discurso empresarial, sendo indicativo não somente de uma mudança semântica - na medida em que substitui o termo qualificação -, mas também das transformações econômicas e políticas ocorridas nos países centrais nas últimas décadas. Apesar da imprecisão quanto ao significado do termo, Moraes (1999, p.25) ressalta o fato desse conceito enfatizar o desempenho de cada indivíduo em situação de trabalho, indicando a individualização crescente da apreciação dos assalariados.

Além dessas questões, Hirata (1998) e Moraes (1999) assinalam que a lógica da competência baseia-se no modelo das grandes empresas dos países desenvolvidos, com intensa utilização de tecnologia e força de trabalho masculina, não contemplando situações de trabalho que fujam a esse padrão. Finalmente, consideram que o conceito pode ser associado ao de empregabilidade, dado que, além de terem em comum o uso patronal (HIRAT A, 1998), ambos têm como referência o indivíduo. Nesse sentido, “um trabalhador 'não empregável' é um trabalhador não formado para o emprego, não competente” (MORAES, 1999, p.25). Hirata (1998) ressalta, ainda, que tant o o termo empregabilidade quanto o termo competência apresentam contomos ainda indefinidos, prestando-se a usos diversos (e imprecisos).

Outra autora a abordar a questão da competência, Deluiz (1995) utiliza o conceito para referir-se ao conjunto mais amplo de aptidões e qualificações que passa a ser exigido dos profissionais no contexto produtivo marcado por inovações tecnológicas. Ao apontar as competências técnicas, organizacionais/metódicas, comunicativas, sociais e comportamentais como aquelas que precisam ser desenvolvidas para fazer frente às novas exigências do mundo do trabalho, a autora incorpora, em parte, o modelo apresentado por Zarifian. A conquista dessas competências requer, segundo Deluiz, a revisão dos métodos tradicionais de ensino, de forma a torná-los menos especializados e fragmentados.

Para Souza, Santana e Deluiz (1999), o modelo de competências incorpora a perspectiva que aponta para o aumento das qualificações exigidas em decorrência da intensificação da modemização produtiva. O trabalhador competente seria aquele para o qual o “saber-ser” suplantaria o “saber-fazer”. Essa mudança também é percebida por Desaulniers (1993), ao ressaltar que "a qualificação social (saber ser) tende a ocupar, cada vez mais e em numerosos setores, o lugar da qualificação propriamente dita (saber fazer).” Nesse sentido, a competência implicaria a capacidade do indivíduo utilizar o conjunto de conhecimentos e capacidades obtidos de formas diversas nas situações de trabalho vivenciadas. Esse conjunto de conhecimentos, no entanto, não seria passível de ser adquirido somente através da formação escolar, uma vez que pressupõe "saberes tácitos e informais”. 
No ambiente empresarial, o uso do termo também é crescente, como se pode constatar a partir do modelo Xerox de competências, descrito por Maurício (1998 apud Chinelli, 200 ?). De acordo com o modelo, competência é vista como o somatório das capacidades e habilidades individuais do empregado, a quem é delegada a iniciativa de procurar suas opções de desenvolvimento de aptidões. A definição de competência para a Xerox seria, na realidade, a busca de cada pessoa por essa definição, a partir do seu próprio processo de desenvolvimento, sendo que o modelo de competência em questão não é estático, mas foi construído para ser flexível, pois entende-se que as competências que têm que ser desenvolvidas hoje podem não ser mais as de amanhã.

Não obstante as diferenças apresentadas quanto à definição do termo competência, cabe assinalar que as abordagens estudadas têm em comum a acepção do conceito com um sentido mais amplo do que o de qualificação. Trata-se de uma noção que remete à esfera individual a responsabilidade pela conquista do emprego e que visa mobilizar a subjetividade do trabalhador em prol do processo produtivo.

\section{O perfil do novo profissional}

Na tentativa de identificar elementos de consenso em tomo das qualificações profissionais requeridas no mundo do trabalho, Paiva (1997) produz artigo em que aponta aqueles que seriam os principais requisitos da força de trabalho contemporânea. Para a autora, as virtudes intelectuais definiriam a competência do trabalhador, expressas na

elevada capacidade de abstração, de concentração e de exatidão, ao lado da capacidade de comunicação verbal, oral e visual, somadas ao pensamento conceptual abstrato como fundamento da ampliação das possibilidades de percepção e de raciocínio, de manipulação mental de modelos, de compreensão de tendências e de processos globais [...]. (PAIVA, 1997, p.123)

A valorização da "qualificação intelectual de natureza geral e abstrata" seria a base sobre a qual se construiriam habilidades mais específicas. Assiste-se ao aumento da complexidade e da cobrança de resultados do trabalho em todos os níveis, requerendo não só uma educação geral de melhor qualidade, mas também "conhecimentos especializados sujeitos a uma pressão permanente de atualização e adição” (PAIVA, 1997, p.124). Segundo a aut ora, essas novas exigências levariam à valorização de um ensino mais eficiente, pondo em xeque as práticas não diretivas de ensino e o "populismo pedagógico".

A popularização crescente de máquinas e computadores passaria a exigir novas habilidades tanto do trabalhador intelectual tradicional, quanto do trabalhador manual, reduzindo as fronteiras e revendo as relações entre essas duas posições. Eleva-se a qualificação profissional média; profissões tradicionais se tornam mais complexas, ao mesmo tempo em que perdem status. Esse conjunto de transformações, no dizer da autora, aponta na direção do incremento da polivalência e das habilidades cognitivas.

A síntese do perfil do profissional contemporâneo pode ser expressa pela combinação de "formação geral sólida, virtudes e disposições sociomotivacionais" que serviriam de base a uma "socialização profissional aberta à reprofissionalização ao longo da vida” (PAIVA, 1997, p.129). Essa combinação pressupõe a revalorização da educação geral, que deve embasar a qualificação específica. Paiva (1997, p.129) afirma, ainda, que um contexto de "abundância de força de trabalho qualificada [...] faz crescer a importância do capital social para a inserção e permanência no mercado de trabalho". As carreiras tornam-se fluidas, exige-se do trabalhador versatilidade e capacidade de se "auto-empresariar", assumindo os riscos pelas mudanças em sua trajetória profissional.

Para a autora, “a qualificação real, o saber fazer, o saber comportar-se de acordo com as situações diversas, o saber mostrar adequadamente a capacidade de acionar conhecimentos e virtudes, tomou-se mais import ante que a qualificação formal” (PAIVA, 1998, p.17). É essa qualificação real que autora identifica como sinônimo de competência, conforme utilizada por Zarifian (1998 apud P AIVA, 1999, p.129).

Conclusões semelhantes à de Paiva quanto ao novo perfil do trabalhador constam do documento Formação Profissional Senac (1996). Compondo esse perfil são identificadas as seguintes características: 
capacidade de raciocínio abstrato, de autogerenciamento, de assimilação de novas informações; compreensão das bases gerais, científico-técnicas, socia is e econômicas da produção em seu conjunto; a aquisição de habilidades de natureza conceitual e operacional; o domínio das atividades específicas e conexas; a flexibilidade intelectual no trato de situações cambiantes tornam-se requisitos do novo profissional. (SENAC, 1996, p.15)

Ao lado dessas, as capacidades de trabalhar em grupo, de compreender o contexto geral de operação da empresa e de se "auto-empresariar" são valorizadas no documento. Para o Senac, o domínio desse conjunto de capacidades pressupõe uma ampla base de educação geral. Talvez, o aspecto mais importante a destacar desse conjunto de características seja o que faz referência às atitudes e disposições comportamentais que passam a ser requeridas desse novo profissional, expressas nas noções de "auto-empresariamento", "saber comportar-se” e “disposições sociomotivacionais”. Apesar de ser fluido seu perfil técnico, sua atitude não o é: o set or produtivo modemizado passa a requerer um profissional comprometido não somente de forma objetiva, mas, principalmente, subjetiva.

\section{Novas experiências no ensino de administração}

As transformações recentes na sociedade e no mercado de trabalho motivaram o MEC a definir novas diretrizes para os cursos universitários no Brasil. A mudança mais radical na filosofia do ensino superior brasileiro ocorreu em 1995, com a lei no 9.131, que conferiu à Câmara de Educação Superior do Conselho Nacional de Educação a competência para deliberar sobre as Diretrizes Curriculares e, no ano seguinte, com a Lei de Diretrizes Básicas n9 9.394, que extinguiu a necessidade de currículos mínimos e ampliou o ano letivo de 180 para 200 dias úteis, além de outras reorientações. Essa grande reestruturação entendia ser direito e dever das universidades, a inovação e o atendimento a demandas regionalizadas, desburocratizando seus cursos e alinhando-se com as tendências e clamores da sociedade brasileira (ANDRADE; AMBONI, 2003).

Essas mudanças vêm impulsionando as instituições de ensino superior (IES) a reverem a estrutura de seus cursos, com vistas a sintonizar a formação oferecida aos graduandos com as atuais exigências do mercado de trabalho. No caso específico dos cursos de graduação em administração de empresas, uma análise da produção cient ífica apresentada nos últimos Enanpads, evidenciou a preocupação das IES com a adequação da formação oferecida aos estudantes de administração à demanda do mercado de trabalho. Do conjunto de trabalhos, sobressaem aqueles que analisam as revisões dos conteúdos tradicionalmente ministrados nas IES e os que relatam experiências inovadoras que visam formar o "novo profissional” de administração de empresas. Além desses estudos, há ainda trabalhos como o de Pereira, Brito e Amâncio (2004), dedicado a analisar o impacto, junto ao corpo docente de uma IES mineira, das reformas curriculares implementadas, tendo como referência as Novas Diretrizes Curriculares para os Cursos de Graduação.

Em trabalho apresentado no XXVII Enanpad sobre uma experiência inovadora no ensino de administração em uma IES mineira, Lisboa, Espigão e Silva (2003) descrevem o projeto implementado por essa IES, denominado Adote um Bairro, com o objetivo de aproximar a formação oferecida das exigências do mercado de trabalho. Segundo os autores, no esforço de adequar seu projeto pedagógico às novas demandas do mundo do trabalho, essa IES toma como base as descrições sobre essas transformações que constam na produção acadêmica de educadores brasileiros como Franco, Frigotto, Machado, Gonçalves e Felício Jr. (apud LISBOA; ESPIGÃO; SILVA, 2003) sobre o tema e as diretrizes mundiais para a educação presentes no Relatório da Unesco de 2000, além de uma pesquisa realizada pelo Conselho Federal de Administração em 1999 sobre percepções acerca do curso de administração. O objetivo do referido projeto é aproximar teoria e prática - levando os estudantes a vivenciarem o desafio de orientar empresas na gerência de seus negócios -, respondendo, assim, à necessidade de

formar profissionais mais bem preparados para atuarem em um mercado que exige novas competências e, ao mesmo tempo, manter a coerência de formação de um ser pensante, questionador $e$ participativo do ambiente e do seu tempo. (LISBOA; ESPIGÃO; SILVA, 2003, p.3) 
Apesar da orientação central da IES adequar seu projeto pedagógico aos desafios do mercado de trabalho, cabe destacar que a referência empírica ao mercado limita-se a informações provenientes da pesquisa realizada pelo Conselho Federal de Administração em 1999. No mais, as orientações apresentadas no estudo provêm de literatura de corte marxista, que versa sobre as mudanças no mundo do trabalho e o seu impacto na educação. Assim, produz-se um casamento pouco ortodoxo entre críticosferrenhos da instrumentalização da educação,tal como Frigotto (2001), e pesquisas eminentemente instrumentais, como a realizada pelo Conselho Federal de Administração, que visa identificar as demandas do setor empresarial no que tange à formação dos futuros administradores.

Entretanto, o que chama at enção neste estudo é o fato de que, apesar do "mercado" ser o suposto motivador das mudanças pedagógicas empreendidas pela IES, ele é perscrutado somente a partir de dados secundários provenientes da pesquisa do Conselho Federal de Administração. Não há qualquer referência a pesquisas feitas no mercado diretamente pela própria IES. Na verdade, a ênfase dada no estudo à formação do aluno visando tomá-lo "agente ativo de um processo de construção social do seu saber”, além de "capaz de atualizar, aprofundar e enriquecer seus conhecimentos, ou seja, tomar-se responsável pelo seu próprio desenvolvimento" (UNESCO, 2000 apud LISBOA; ESPIGÃO; SILVA, 2003, p.6) sugere que as inovações pedagógicas estão mais comprometidas com a abordagem dos educadores citados - preocupados com a formação integral do aluno - do que com o mercado propriamente dito. O paradoxo entre o referencial teórico orientador desse projeto de mudança e a intenção de preparar profissionais demandados pelo mercado, pode ser visto como um indicador da dificuldade que as IES enfrentam diante do desafio de adequarem seus cursos de graduação ao mercado de trabalho atual.

A adoção de novas estratégias pedagógicas no curso de Administração de Empresas da PUC-MG, em sua unidade de Betim, também foi tema da análise de Rossi, Ribeiro e Teodósio (2004). A preocupação com a integração entre teoria e prática norteou o projeto pedagógico do curso de administração desde a sua criação em 1995, tendo contado com a participação de alunos e professores no seu delineamento. Apesar desse projeto ter sofrido alterações desde então, os autores destacam a permanência do denominado "trabalho integrado", desenhado com o intuito de articularteoria e prática, "proporcionando uma formação que reforça o papel social da administração e do profissional como agente de transformação" (ROSSI; RIBEIRO; TEODÓSIO, 2004, p.9).

Nessa experiência, cabe ressaltar o fato do projeto pedagógico formulado em consonância com as transformações sociais recentes, ter como referência a "sociedade”, em sentido mais amplo, e não o "mercado". Na contramão do discurso que tende a predominar em outras IES, a PUC de Betim critica a posição de "refém do mercado" e orienta suas atividades visando à "construção de um sujeito acadêmico" (ROSSI; RIBEIRO; TEODÓSIO, 2004, p.5). Na escolha das organizações que servirão de referência para a elaboração de seus trabalhos integrados, os alunos são incent ivados a privilegiarem organizações do terceiro set or, por entender-se que essa opção fortalece o papel do administrador como “agente detransformação social”.

O trabalho elaborado por Perera et al (2004) buscou avaliar em que medida uma faculdade de administração de São Paulo vem sendo bem-sucedida em sua missão de formar empreendedores. A formulação do problema de pesquisa e a motivação desse estudo relacionam-se diretamente ao pressuposto de que as transformações recentes do mundo do trabalho apontam para a necessidade de profissionais empreendedores, notadamente, na área de administração. Apesar do objetivo do estudo ser verificar se a IES vem sendo bem sucedida na tarefa de formar empreendedores - e não o de averiguar se o mercado efetivamente demanda esse tipo de profissional-, cabe dest acar, também nesse estudo, que a “demanda do mercado" por empreendedores aparece como um dado de realidade, tendo como única referência a literatura sobre o tema. A pesquisa empírica realizada dedicou-se, portanto, a estimar o perfil empreendedor dos profissionais formados pela IES.

Outra experiência inovadora no ensino de administração - o caso do curso de graduação da Unisinos - merece destaque tanto pela ousadia do projeto, quanto pelo fato deste ter sido elaborado tendo como ponto-de-partida a necessidade dos cursos de administração manterem forte vinculação com o mercado. O trabalho de Borba, Silveira e Faggion (2004) descreve o curso (implementado a partir de 2003), que adota o modelo pedagógico 
interacionista/construtivista. Por estar em seu segundo ano de implementação, a análise dos resultados do projeto é limitada, ainda que a experiência seja descrita como bastante enriquecedora para docentes e discentes.

Conforme dito anteriormente, no caso da Unisinos, a preocupação em vincular o projeto implementado à demanda efetiva do mercado de trabalho da região contrasta com as outras iniciativas de mudanças relatadas. $\mathrm{O}$ desenho do novo curso foi precedido de pesquisas realizadas junto aos potenciais alunos de administração, aos alunos matriculados em cursos de administração e a organizações gaúchas de naturezas diversas (num total de 208 organizações consultadas). No que diz respeito à demanda do mercado, cabe destacar as principais conclusões da pesquisa, resultantes de entrevistas com dirigentes e represent antes de empresas:

[...] são relevantes as capacidades de tomada de decisão e de negociação, bem como a capacidade de trabalhar em equipe. Destaca-se, tam bém, a relevância dada ao espírito empreendedor do profissional de adm inistração. Chama a atenção que as empresas não conferem muita importância aos conteúdos específicos tradicionalm ente trabalhados na Academia, mas sim ao desenvolvimento de determinadas competências e habilidades dos administradores (grifo nosso). (BORBA; SILVEIRA; FAGGION, 2004, p.6)

Nesse estudo, a pesquisa realizada nas empresas deu consistência à proposta de reforma curricular posteriormente implementada, e seu caráter inovador - notadamente, quanto à metodologia de ensino adotada resulta da percepção de que, mais do que conhecimentos teóricos diferenciados, o mercado parece demandar at it udes diferenciadas.

Conforme a análise dessas experiências recentes indicou, a preocupação crescente das IES e dos pesquisadores com a adequação da formação dos futuros administradbres às demandas do mercado de trabalho contrasta com o número restrito de estudos dedicados a perscrutar diretamente as demandas efetivas desse mercado. Num afã de formar administradores adaptados ao novo mundo do trabalho, o esforço das IES para rever conteúdos e metodologias de ensino tem se baseado muito mais em conclusões oriundas de debates entre seus docentes e dirigentes (ou em orientações provenientes da literatura recente dedicada a discutir os desafios do mundo do trabalho) do que em estudos empíricos que tenham empreendido.

Muitas vezes, mudanças são propostas levando-se em conta uma duvidosa comparação com competidores de outras áreas - notadamente, de engenharia de produção -, o que facilita uma postura reativa das IES de administração de empresas, as quais buscam copiar modelos exógenos à sua realidade e tradição. Sem desconsiderar a relevância daquelas fontes de informação, acreditamos que pesquisas dedicadas a identificar as expect ativas das empresas ao recrutarem seus futuros gerentes podem acrescentar novas informações ao debate sobre a formação do administrador. Foi essa convicção que motivou o esforço de conhecer melhor as expectativas do mercado através de entrevistas com profissionais de recursos humanos, cujas principais conclusões são apresentadas na próxima seção.

\section{A demanda do mercado}

As principais questões que estruturaram a pesquisa acerca das atuais demandas do mercado de trabalho envolveram o desenho do perfil desejado para um profissional de gerência, conforme percepção daqueles responsáveis por sua contratação. Esse mapeamento baseou-se em duas perguntas fundamentais, dirigidas aos entrevistados, a saber: 1)“Para a sua empresa, quais as características desejáveis, tanto do ponto de vista de conhecimentos específicos, quanto no que se refere a habilidades, para um profissional que futuramente ocupará posições de gerência?” e 2)“ O que sua empresa valoriza ao recrutar e selecionar seus trainees? ” Tais indagações foram o ponto de partida da abordagem aos entrevistados, com diferentes desdobramentos ao longo das entrevistas.

Ao responderem a tais perguntas, os entrevistados surpreenderam os pesquisadores, ao enfatizarem os aspectos comportamentais em detrimento de conhecimentos específicos. Por se tratar de posições de trainees, a maioria dos entrevistados alegou que esses profissionais serão treinados, adquirindo na própria empresa os conhecimentos específicos durante e após o programa que antecede a ocupação dos cargos gerenciais. 
Ademais, conforme observou uma entrevistada, gestora da área de RH de uma empresa filiada à indústria química, o próprio conhecimento adquirido na universidade tem prazo de validade relativamente curto, diante de um mercado instável e em mutação. Mais importante seria, portanto, a capacidade de adquirir novos conhecimentos e de saber o que fazer com eles.

Análise, síntese, comunicação, propensão ao risco e capacidade de “fazer acontecer” foram termos recorrentes nesse mapeamento de competências desejadas. Essa menção à capacidade de realização ficou explicitada na entrevista com o gerente de uma empresa de navegação, que afirmou que a "capacidade de formular e implementar projetos” era a principal competência que observava em um candidato. Essa competência, asseverou, deveria estar associada a uma habilidade comunicativa, visto que o sucesso de projetos complexos “está associado à rede de relacionamentos e à forma como um líder negocia”. Para esse gest or, a "formação generalista de um gerente é crucial, assim como a sua capacidade de fazer e manter relações”. Tal análise encontra paridade na afirmação de uma entrevistada, at uante na área de telefonia, a qual citou sua experiência com vários trainees que setransformaram em gerentes em sua empresa. Segundo sua argument ação,

O item que mais se relaciona com o sucesso do futuro gestor é a sua capacidade de identificar problemas e encontrar soluções, (pois) bom gestor é aquele que se vira, mas encontra uma forma de atingir os resultados. Para isso, é necessário que o ocupante do cargo tenha iniciativa, capacidade de comunicação e visão ampla do negócio. Não preciso de um excelente técnico que não saiba como sua atuação interfere no business. (A, DIRETORA DE MARCA E COMUNICAÇÃO DA EMPRESA DE TELEFONIA 1 - ENTREVISTA PESSOAL, 23 DE NOVEMBRO DE 2005)

Ainda no setor de telefonia, uma gerente de RH de uma empresa multinacional informou não ser possível garant ir que um determinado trainee irá para uma área específica. Ela disse que (as condições de mercado)

impõem lacunas no quadro gerencial da empresa, e as oportunidades intemas surgem de forma nem sempre estruturada. Assim, tem melhores condições de ascensão profissional aquele candidato mais flexível e que aceite desafios e riscos, e é esse o preferido na fase de contratação. Conhecimentos técnicos fundamentais são importantes, pois, sem eles, a empresa teria que despender energia para ensinar conteúdos que já deveriam estar dominados, mas não é a demonstração de que detém conhecimentos sofisticados que deixará o candidato a tra inee em posição de vantagem em relação aos demais. Nesse setor, as mudanças são muito impactantes, e uma nova tecnologia é capaz de mudar radicalmente conhecimentos adquiridos. A adaptação a essa ciranda alucinada é questão de vida ou morte na (e da) empresa. (B, GERENTE DE DESENVOLVIMENTO DA EMPRESA DE TELEFONIA 2 - ENTREVISTA PESSOAL, 14 DE FEVEREIRO DE 2006)

Vale ressaltar que não apenas a questão tecnológica, citada em várias entrevistas, merece at enção, mas também as questões de caráter organizacional, como demonstra a fala desta gerente:

Essas empresas [de telefonia], no mais das vezes, são oriundas de joint ventures e fusões, e sua transformação interna é constante, tanto nos níveis gerenciais, quanto no de composição acionária. Uma pessoa "apenas técnica" terá pouca chance de se estabelecer nesse cenário, ainda que trabalhe nas muitas áreas técnicas da empresa. (B, GERENTE DE DESENVOLVIMENTO DA EMPRESA DE TELEFONIA 2 - ENTREVISTA PESSOAL, 14 DE FEVEREIRO DE 2006)

Se a importância da formação específica ficou minorada, suscita interesse, todavia, a observação feita pelo gestor da empresa de navegação no que se refere aos principais conhecimentos que um gestor deve possuir ao sair da graduação. “É prioritário o domínio de conceitos básicos de marketing e estratégia”, afirma. Tal percepção, talvez, possa ser explicada pelo exercício de se olhar o outro, de diferentes formas (o que tais temas exigem), alinhando-os com as características comportamentais demandadas.

No caso dos formados em administração de empresas, candidatos naturais a cargos de trainees de gerência, ficou claro que eles concorrem diretamente com egressos dos cursos de engenharia (principalmente, de produção), economia, ciências contábeis e, em alguns casos, com egressos dos cursos de psicologia e de comunicação. Não obstante, conforme apontou o gestor de uma empresa química, os egressos de cursos de 
engenharia de produção são os que mais se aproximam de sua demanda, por unirem sólido conhecimento matemático, “afinal, são engenheiros”, com uma boa visão de negócios. Em suas palavras, "normalmente, eles são melhores do que os administradores porque eles têm mais disciplina”. Essa visão encontra respaldo na argumentação da gestora da empresa de telefonia 1, que citou, como exemplo, as dinâmicas de grupo do processo seletivo, sob sua responsabilidade, nas quais, sistematicamente, os engenheiros de produção se destacam,

não porque conhecem matemática, mas porque conseguem, mais facilmente, estabelecer associações entre áreas distintas, sejam elas quantitativas ou qualitativas. A prática tem mostrado que estes, nas dinâmicas, são mais capazes de observar um problema sob ângulos diferentes do que os provenientes de outros cursos. (A, DIRETORA DE MARCA E COMUNICAÇÃO DA EMPRESA DE TELEFONIA 1 - ENTREVISTA PESSOAL, 23 DE NOVEMBRO DE 2005)

No desenvolvimento de sua fala, essa gestora citou o exemplo de uma dinâmica que acabara de conduzir, na qual o candidato oriundo da área de engenharia de produção fora o único a considerar dimensões mercadológicas, éticas e técnicas na solução proposta ao caso dado. Com isso, afirmou a entrevistada, "ele se destacou do grupo".

Ao ser questionada sobre a importância de conhecimentos matemáticos pelo futuro gestor, uma das entrevistadas - sócia de uma consultoria de recursos humanos responsável pelo processo de seleção de várias empresas privadas - respondeu que,

mais importante que os conteúdos, é a capacidade analítica que o raciocínio matemático desenvolve. Por outro lado, conhecimentos de informática (softwares específicos) e fluência em outros idiomas (principalmente, o inglês), são fundamentais, de preferência quando associadas a experiências no exterior. (C, SÓCIA DA CONSULTORIA 1 - ENTREVISTA PESSOAL, 6 DE OUTUBRO DE 2005).

O gerente da empresa de navegação entende que os candidatos a trainee têm se mostrado "fracos", ano após ano. Suas palavras suscitam considerações. Segundo ele, raramente, surge alguém com uma visão ampla das questões apresentadas, e quando isso ocorre, “certamente, essa pessoa já teve experiências no exterior ou já cursou mais de uma faculdade”. Se, de um lado, essa observação corrobora a percepção da gestora da empresa de telefonia 1 e a da sócia da consultoria 1, citadas anteriormente, de outro, acrescenta um novo elemento à análise, que é a reduzida idade dos egressos. A pouca idade, no entanto, coloca-os numa armadilha, pois ao mesmo que é preciso que sejam jovens para terem disposição e disponibilidade integral para o mercado de trabalho, também é necessário que tenham experiência para melhor compreender o complexo mundo que os cerca. Talvez, essa seja uma questão que não encontre resposta na atual estrutura de formação profissional.

Esse aspecto está vinculado a outro elemento que surgiu espontaneamente em várias entrevistas, que foi a origem do postulante ao cargo de trainee. Se, em alguns casos, a formação acadêmica específica não importa tanto para a inclusão do candidato no processo seletivo, a conclusão do terceiro grau numa "instituição conceituada” é um dado digno de nota. Ainda que não se afirme ser esta uma prática oficial das empresas em questão, o renome da instituição de ensino é levado em consideração, funcionando como um primeiro filtro, mesmo que seja reconhecida a existência de bons potenciais em faculdades que não sejam tidas como de primeira linha. O difícil é

esse aluno [de uma instituição que não é de primeira linha] ter acesso às dinâmicas para demonstrar suas habilidades”, [visto que] a origem acadêmica do candidato é, normalmente, definida pelos meus clientes. Para cargos de gerência, as faculdades, sejam elas quais forem, devem ter "bom desempenho", o que pode ser entendido como A no Provão do MEC, ou ter uma boa reputação. ( $D$, ANALISTA DE RH DA CONSULTORIA 2 - ENTREVISTA PESSOAL, 28 DE NOVEMBRO DE 2005)

Alinhada com esse ponto de vista, está outra entrevistada, profissional de recursos humanos de um grande banco privado. Ela ressaltou que a formação específica não diferencia os candidatos a trainee de gerência no banco, mas, sim, a faculdade de onde vêm, acrescentando que são recrutados apenas os egressos de instituições que receberam conceito A no extinto Provão do MEC. 
Ambos os depoimentos vão ao encontro das conclusões de Coelho (2001) num estudo sobre as convergências e as divergências entre educação superior e mercado de trabalho no Brasil. Esse aut or destaca que, ao analisar os cadernos de empregos dos principais jornais brasileiros, observara que nos anúncios para cargos de nível superior, a procura não mais se restringia a diplomados de uma área específica. Coelho (2001, p.4) verificou que "para um cargo de gerente de agência bancária, por exemplo, muitas vezes, não importa se a formação do candidato é administração, economia, contabilidade, engenharia ou processamos de dados”.

Tais percepções se afinam com o que se poderia chamar de “at ivo social do candidato”, expressão utilizada pela sócia da empresa de consultoria. Por trás dessa terminologia, existe a busca por um candidato cuja posição social tenha lhe possibilitado vivência no exterior, garantido acesso aos melhores (e mais caros) cursos de graduação, de línguas e de artes, além da constituição de uma rica rede de contatos, resultante, muitos vezes, de relacionamentos familiares. Esse conceito resume várias exigências, formais ou não, mencionadas anteriormente. Logo, a formação do candidato passa a ser um dos tópicos de uma gama complexa de elementos considerados na contratação de um trainee; dos quais os aspectos comportamentais foram os mais citados.

\section{Conclusão}

Essa investigação teve por objetivo identificar quais as principais características desejadas para o profissional recém-formado que será contratado para se transformar em gerente, segundo o olhar de grandes empresas privadas fluminenses. Parte da premissa de que existem requisitos técnicos, bem como algumas características comportamentais, que são mais valorizados por estarem alinhados com a realidade de mercado dessas corporações.

As informações obtidas nas entrevistas confirmaram, em parte, as propostas iniciais da pesquisa. De fato, tanto os aspectos cognitivos referentes à formação do postulante ao cargo de trainee, quanto suas características comportamentais foram identificados como uma preocupação dos recrutadores, conforme hipótese do estudo. Todavia, ficou evidenciado que a dupla at enção aos traços comportamentais e aos ativos sociais do candidato supera a preocupação com formação técnica específica do futuro gerente, de acordo com o olhar daqueles responsáveis por sua contratação. As ferramentas e as dinâmicas utilizadas no processo seletivo refletem tal ênfase.

A valorização de aspectos referentes mais às atitudes dos candidatos do que aos seus conhecimentos formais vai ao encontro das percepções de Paiva (1997), Souza et alli (1999) e de Zarifian (1998) acerca das novas exigências do mercado de trabalho. A julgar pelos depoimentos dos entrevistados, cada vez mais, as empresas esperam de seus funcionários a capacidade de "se mobilizar subjetivamente" (ZARIFIAN,1998), capacidade essa expressa na expectativa por um trabalhador com iniciativa, capacidade de resolver problemas e de saber o que fazer com os conhecimentos adquiridos. Conforme já se disse, atitudes e disposições comportamentais importam mais do que conhecimentos técnicos específicos ou, nos termos de Souza et alli (1999, p.47), “o 'saber-ser' suplantaria o 'saber-fazer'”.

As empresas abordadas confirmaram, também, a valorização do perfil generalista, em detrimento do especialista; a capacidade de adaptação a situações novas, e não a rejeição ao risco; a aptidão ao trabalho sobre pressão, ao invés da propensão à estabilidade; as habilidades de liderança e de atuação em equipe, em vez do gosto pelo trabalho solitário; a solidariedade e a ética no alcance dos objetivos, e não o prejuízo do sucesso predatório. Logo, saber lidar com pessoas, ter equilíbrio emocional, possuir sensibilidade social e exercitar uma postura investigativa sobre o seu entorno são diferenciais reconhecidos nessas empresas. Essas constatações, oriundas do trabalho de campo, também encontram respaldo na teoria, quando se afirma que a universidade deveria desenvolver atributos como "visão estratégica, capacidade de tomar decisões, capacidade de liderar e de trabalhar em equipe, criatividade e habilidade de convívio interpessoal" (BORBA; SILVEIRA; FAGGION, 2004, p.6). Resta a dúvida se a prática da formação acadêmica tradicional, voltada a conteúdos, é capaz de suprir essa demanda.

O discurso dos entrevistados converge para exigências comuns, ainda que a origem e a área de at uação de suas empresas sejam distintas. Ficou evidenciado, no decorrer das entrevistas, que a mobilidade dentro da empresa, 
as transformações sociais e tecnológicas e a instabilidade mercadológica at enuam a necessidade de um domínio de cont eúdos específicos aprendidos na graduação. A capacidade de lidar com o novo, de articular e negociar com outras pessoas (internas e externas à organização), de tomar decisões em situação de risco e de fazer associações entre áreas distintas são os principais elementos que diferenciam um gerente de sucesso dos demais.

A despeito do visível alinhamento dessa constatação da pesquisa com o posicionamento dado pelas novas diretrizes curriculares, não fica tão claro o quanto as IES preparam seus alunos para responderem a essas demandas. Nesse sentido, cabe lembrar que as alterações comportamentais que vêm sendo cada vez mais enfatizadas pelo mercado impõem mudanças importantes na estrut ura física e administrativa das IES, na cultura e, principalmente, na preparação dos docentes para enfrentarem esses novos desafios. A análise de experiências recentes de mudanças nos cursos de administração de algumas IES revelou não só dificuldades conceituais na condução desses processos como uma carência de informações consistentes sobre a demanda do mercado de trabalho: basta lembrar que, excetuando a Unisinos, as demais IES que relataram suas experiências inovadoras não realizaram pesquisas capazes de perscrutar, efetivamente, as expectat ivas do mercado.

Tendo em vista as limitações enfrentadas pelas IES ao prepararem os futuros administradores, as empresas buscam minimizar eventuais carências na formação do egresso, priorizando os centros de excelência de formação como fonte de recrutamento de seus candidatos. Apesar desses centros se mostrarem mais aptos a fornecer os profissionais capazes de atender às exigências das empresas, cabe indagar se esse êxito é decorrente da atuação da instituição na formação do aluno ou se essa eficiência é resultado das caract erísticas pessoais e, por vezes, sociais do discente que ela tende a atrair -0 ativo social mencionado por uma entrevistada.

Outra possível razão para a escolha de "centros de excelência”, expressão ouvida repetidas vezes, é a ligação nem sempre clara entre os contratantes da empresa e a realidade acadêmica. Por vezes - talvez, devido à sobrecarga de trabalho e à pressa em preencher os cargos de que se necessita - os responsáveis na empresa não procurem pesquisar, averiguando detalhadamente a formação profissional oferecida por cada instituição. Nesses casos, recorrer ao nome da instituição é uma solução com poucos riscos internos para o encarregado de contratar. Essa possibilidade requereria uma investigação específica, mas, a ser verdade, sugere uma componente imagética na definição de quem vai ou não ser contratado.

Fechando esse ciclo, seria razoável supor que os futuros aspirantes a gerentes também levam em consideração esse elemento na hora de escolher sua faculdade. Logo, as melhores faculdades têm os melhores níveis de contrat ação de seus egressos porque têm os melhores alunos, fruto de uma disputa mais acirrada no vestibular como é o caso de alguns cursos de engenharia de produção -, etêm os melhores alunos porque estes sabem que terão maiores probabilidades de contratação pelo mercado. Nessa retroalimentação, a contribuição da universidade ficaria submetida mais a sua imagem de mercado, do que a sua competência formadora.

O desafio posto às universidades - especialmente, nos cursos de graduação em administração de empresas - de propiciar uma formação consistente com a demanda do mercado de trabalho aumenta no contexto atual. A origem taylorista da formação do administrador, ressaltada por Zarifian (1998), mostra-se irreconciliável com a atual realidade social, na qual se inserem as empresas. Por esse motivo, cabe aos centros responsáveis pela formação de gestores diminuírem a distância entre o universo acadêmico e a realidade empresarial. Urge, portanto, uma discussão mais profunda sobre qual o papel que esses centros de geração de conhecimento desejam em sua inserção social. Este artigo pode ser considerado um pequeno passo nessa direção. 


\section{Referências}

AMADEO, Edward. Dez pontos sobre a situação recente do mercado de trabalho. Brasília: Ministério do Trabalho, ago. 1998. (Notas sobre o Mercado deTrabalho, n.5).

ANDRADE, Rui Otávio; AMBONI, Nério. Diretrizes curriculares para o curso de graduação em administração. Brasília: Conselho Federal de A dministração, 2003.

BARROS, Ricardo Paes; COSSIO, Maurício Blanco; TELES, Jorge Luiz. A eficácia das políticas de trabalho e renda no combate à pobreza. In: VELLOSO, J oão Paulo dos Reis et alii. (Coord.). Soluções para a questão do emprego - Fórum Nacional. Rio de J aneiro: J osé Olympio, 2001.

BORBA, Gustavo; SILVEIRA, Teniza; FAGGION, Gilberto. Praticando o que ensinamos: inovação na oferta do curso de graduação em administração - gestão para a inovação e liderança na U nisinos. I n: ENCONTRO NACIONALDE PROGRAMAS DE PÓS-GRADUAÇÃO EM ADMINISTRAÇÃO, 28., 2004, Curitiba. Anais... Curitiba: Enanpad, 2004. CD -ROM.

CASTEL, Robert. As metamorfoses da questão social: uma crônica do salariado. Petrópolis: Vozes, 1998.

CHINELU, Filippina. A construção da noção de empregabilidade: esboço de mapeamento do debate no Brasil. Rio de J aneiro, [200-?]. Mimeografado.

COELHO, Fernando S. A educação superior brasileira: convergências e divergências com o mundo do trabalho. In: ENCONTRO NACIONAL DE PROGRAMAS DE PÓS-GRADUAÇÃO EM ADMINISTRAÇÃO, 26., 2001, Campinas. Anais... Campinas: Enanpad, 2001. CD-ROM.

COUTINHO, Luciano. A especialização regressiva: um balanço do desempenho industrial pós-estabilização. I n: VELLOSO, J oão Paulo dos Reis Velloso. (Coord.). Brasil: desafios de um país em transformação. Rio de Janeiro: J osé Olympio, 1997.

DELUIZ, Neise. Formação do trabalhador: produtividade e cidadania. Rio de Janeiro: Shape, 1995.

DESAUINIERS, J ulieta Beatriz. F ormação, qualificação ou competência. Veritas, Porto Alegre, v38, n.149, mar. 1993.

FRIGOTTO, Gaudêncio. Educação, crise do trabalho assalariado e do desenvolvimento: teorias em conflito. I n: FRIGOTTO, Gaudêncio (O rg.). Educação e crise do trabalho: perspectivas de final de século. Petrópolis: Vozes, 2001.

HI RATA, Helena. Competências e divisão social do trabalho no contexto de novos paradigmas produtivos. I n: SEMINÁRIO INTERNACIONAL EDUCAÇÃO PROFISSIONAL, TRABALHO E COMPETÊNCIAS, Rio de J aneiro, 1996. Anais... Senai/DN-Ciet, 1998. p.53-61.

LISBOA, S. A.; ESPIGÃO, H. S.; SI LVA, J. Uma experiência metodológica inovadora no interior mineiro no ensino da administração. I n: ENCONTRO NACIONA LDE PROGRAMAS DE PÓS-GRADUAÇÃO EM ADMINISTRAÇÃO, 27. , 2003, Atibaia. Anais... A tbaia: Enanpad, 2003. CD-ROM.

MORAES, Camen Sylvia. A relação trabalho-educação e o novo conceito de produção: algumas considerações iniciais. I n: DIAGNÓSTICO da formação profissional - ramo metalúrgico. São Paulo: CNM/Rede U nitrabalho, 1999.

MTE/SEFOR. Guia do Planfor 2001. Brasilia: MT/S efor, 2001.

NERI Marcelo; CAMARGO José Márcio; REIS, Maurício Cortez Emprego e produtividade no Brasil na década de 90 . Rio de J aneiro: PUC, out. 1999. (Texto para Discussão, 405).

PAIVA, Vanilda. Desmistificação das profissões: quando as competências reais moldam as formas de inserção no mundo do trabalho. Contemporaneidade e Educação, Rio de J aneiro: IEC, ano II, n. 1, p.117-134, 1997.

Educação e mundo do trabalho: notas sobre formas alternativas de inserção de setores qualificados. Contemporaneidade e Educação, Rio de J aneiro, IEC, ano III , n.4, p.8-21, 1998.

. N ova relação entre educação, economia e sociedade. Contemporaneidade e Educação, Rio de J aneiro, IEC, ano IV, n.6, p.120-132, 1999. 
PEREIRA, Maria C.; BRITO Mozar J. B.; AMÂNCIO, C risthiane O. Construção e reconstrução do currículo no ensino em administração: um estudo de caso. In: ENCONTRO NACIONAL DE PROGRAMAS DE PÓS-GRADUAÇÃO EM ADMINISTRAÇÃO, 28., 2004, Curitiba. Anais... Curitiba: Enanpad, 2004. CD-ROM.

PERERA, L. C. J. et al. Missão: formar empreendedores. I n: ENCONTRO NACIO NAL DE PROGRAMAS DE PÓS-GRADUAÇÃO EM ADMINIST RAÇÃO, 28. , 2004, Curitiba. A nais... Curitiba: Enanpad, 2004. CD-ROM.

POCHMANN, Márcio. O emprego na globalização. São Paulo: Boitempo Editorial, 2001.

RIFKIN, Jeremy. The end of work: the decline of global labor force and the post-market era. New York: Tarcher, 1995.

ROSSI, Maria de Fátima; RIBEI RO, Marco Pólo; TEODÓSIO, Armindo. De gestores a cidadãos: novas estratégias didáticopedagógicas na graduação em administração. In: ENCONTRO NACIONAL DE PROGRAMAS DE PÓS-GRADUAÇÃO EM ADMINISTRAÇÃO, 28., 2004, Curitiba. Anais... Curitiba: Enanpad, 2004. CD-ROM.

SENAC/DN. Formação profissional Senac: uma proposta para o setor de comércio e serviços. Rio de Janeiro: Senac/DN/DFP, 1996.

SOUZA, Donaldo; SANTANA, Marco Aurélio; DELUIZ, Neise. Trabalho e educação: centrais sindicais e reestruturação produtiva no Brasil. Rio de Janeiro: Q uartet, 1999.

ZARIFIAN, Philippe. A gestão da e pela competência. In: SEMINÁRIO INTERNACIONAL EDUCAÇÃO PROFISSIONAL, TRABA IHO E COMPETÊNCIAS. Rio de Janeiro, 1996. Anais... Senai/DN -C iet., 1998. p.15-24.

\footnotetext{
${ }^{1}$ Castel (1998) identifica como sintomas da precarização do emprego, o crescimento dos vínculos de trabalho instáveis, temporários ou intermitentes, a perda de direitos trabalhistas e a queda de remuneração; fatores que levaram à mudanç a no conceito de c arreira.

${ }^{2}$ Implementado durante o governo Fernando Henrique Cardoso (1995-2002) e financiado com recursos do Fundo de Amparo ao Trabalhador (FAT), o Planfor visou garantir oferta de qualificação profissional a parcelas crescentes da população economicamente ativa (PEA), com vistas a contribuir para o aumento da produti vidade do trabal ho e a redução do subemprego.
} 